\title{
GESTÃO E GERENCIAMENTO DE RESÍDUOS SÓLIDOS NO MUNICÍPIO DE CRICIÚMA/SC
}

\author{
SOLID WASTE MANAGEMENT IN THE MUNICIPALITY OF \\ CRICIÚMA/SC
}

\section{Mario Ricardo Guadagnin \\ Professor da Universidade do \\ Extremo Sul Catarinense - \\ UNESC. E-mail:mrg@unesc.net}

Cassandra Costa Selau

Acadêmica do curso de

Engenharia Ambiental e Sanitária - UNESC. E-mail:

selaucassandra@gmail.com

\section{Sabrina Baesso Cadorin}

Acadêmica do Curso de

Engenharia Ambiental e Sanitária

- UNESC. E-mail:

bcadorin.sabrina@gmail.com

\section{RESUMO}

A gestão e o gerenciamento de resíduos sólidos evoluíram no país desde a implementação da Política Nacional de Resíduos Sólidos com a aprovação da lei n. 12.305/2010. Os gestores públicos e demais atores na cadeia de geração pós-consumo de produtos/resíduos devem atuar em consonância com os princípios da responsabilidade compartilhada com destinação ambientalmente adequada de recicláveis, tratamento da fração orgânica e disposição de rejeitos em aterros sanitários. Este trabalho tem como objetivo apresentar a gestão dos resíduos do município de Criciúma - SC através de suas etapas de gerenciamento. A média de geração per capita é de cerca de $0,69 \mathrm{~kg} / \mathrm{hab}$ dia $^{-1}$ de resíduos. Há no município um programa tímido inicial de coleta seletiva na modalidade porta a porta, onde os resíduos são segregados na fonte em orgânico e seletivo recicláveis, sendo que esses são coletados pela empresa terceirizada. A coleta seletiva encaminha os resíduos para duas associações de catadores no município para realizar a triagem e o beneficiamento. A coleta convencional encaminha os resíduos orgânicos e rejeitos para o aterro sanitário da empresa. Opera ainda no município sob os cuidados da Fundação Municipal de Meio Ambiente (FAMCRI) um Ecoponto municipal. Nesse espaço, são recebidos materiais como eletroeletrônicos, madeiras, volumosos e pneus inservíveis. Esse serviço foi implementado a fim de possibilitar um local adequado para descarte destes materiais, evitando o lançamento indevido nas vias públicas. A gestão integrada dos resíduos é fundamental atender aos princípios e diretrizes da Política Nacional de Resíduos Sólidos (PNRS).

Palavras-chave: Resíduos sólidos urbanos. Gestão municipal. Coleta seletiva e convencional.

\section{ABSTRACT}

Solid waste management has evolved in the country since the implementation of the National Solid Waste Policy with the approval of Law 12.305/2010. Public managers and other actors in the postconsumption generation chain of products/waste should act in accordance with the principles of shared responsibility with environmentally appropriate destination of recyclables, treatment of the organic fraction and disposal of waste in landfills. This work had as objective to present the management of the residues of Criciúma-SC - SC through its management stages. The average generation per capita is about $0.69 \mathrm{~kg} /$ inhabitant.day of waste. In the city, there is a timid initial program of selective collection in door to door modality, where the waste is segregated in the source in organic and selective recyclables, and these are collected by the outsourced company. The selective collection sends the waste to two associations of waste collectors in the city to carry out the sorting and processing. The conventional collection sends the organic waste and tailings to the 
company's landfill. Also operating in the city under the care of the Municipal Environment Foundation (FAMCRI) a municipal ecopoint, in this space are received materials such as electric, electronic, wood, bulky and waste tires, this service was implemented in order to provide a suitable place for disposal of these Materials, avoiding undue release on public roads. Integrated waste management is fundamental to comply with the principles and guidelines of the National Solid Waste Policy.

Keywords: Urban solid waste. Municipal management. Selective and conventional collection. 


\section{INTRODUÇÃO}

As atividades humanas simples ou complexas estão amalgamadas no dia a dia com a geração de resíduos sólidos, vulgarmente com o codinome "lixo". São atos, fatos e focos de geração de resíduos o processo de coleta, preparação até o fim da vida útil daquilo que é transformado para atender às necessidades de consumo, quer sejam alimentares (cascas, caroços, folhas, sobras orgânicas) ou de posse individual de objetos, que dão significado e identidade ao indivíduo e conectam com os demais participantes da sociedade (aparelhos de smartphone, iPhone, celulares, tabletes...), após o uso e a perda de significado e significância o descarte destes produtos são transformados em lixo.

A característica das culturas ancestrais até meados do século XX em relação aos dejetos humanos era de livrar-se rapidamente das sobras que não possuíam mais utilidade, além de afastar corpos, dejetos, excrementos, resíduos que eram lançados e dispostos a céu aberto, em ravinas, despenhadeiros, ou beira de rios, eventualmente inumados em sítios enclausurados.

A maneira de viver em que o indivíduo não é participante do território e não mantém relação de pertencimento aos artefatos que conquista torna seus resíduos coisas efêmeras, espontaneamente descartáveis, de valor insignificante e residual.

Os resíduos sólidos gerados e sua destinação ou disposição resultam de uma dinâmica de matéria e energia, relação estabelecida pela sociedade com o ambiente, da ação humana no espaço, e sua territorialidade, intercedida pelo trabalho que reproduz um processo cultural de aprendizagem e um nível de consciência grupal. Dessa forma, as sobras, os dejetos ou resíduos sólidos, o vulgo "lixo", tem existência material e utilitária como algo desvalorizado, descartável, que deve ser apartado, distanciado da presença e vista de todos.

\section{METODOLOGIA}

O trabalho metodologicamente possui o caráter de pesquisa exploratória que visa proporcionar maior familiaridade e aproximação com o tema - problema para conhecer os fatos e fenômenos relacionados com a gestão e o gerenciamento de resíduos sólidos em Criciúma - SC, visita e entrevista com profissionais ligados à operacionalização da coleta de resíduos urbanos, com pesquisa e recuperação de informações disponíveis e análise de dados do Plano Municipal de Resíduos Sólidos.

Este estudo foi realizado por meio de levantamento bibliográfico de diversos autores da área, com revisões bibliográficas e leituras de diferentes obras e autores que discutem o 
gerenciamento de resíduos sólidos (BESEN, 2012; 2014; Candido, 2009, CONSONI; SILVA, GIMENEZ FILHO, 2000; DEMAJOROVIC, LIMA, 2013; EIGENHEER, FERREIRA, J ADLER, 2005; GRIPPI, 2001; MONTEIRO et al., 2001), entre outros.

Essa pesquisa bibliográfica exploratória foi desenvolvida a partir de material já elaborado, constituído principalmente de livros e artigos científicos, e contextualizada para a análise descritiva com um paralelo entre as teorias, o amparo legal com a edição recente da Política Nacional de Resíduos Sólidos, Lei 12305/2020 e a descrição da situação encontrada no município de Criciúma - SC. A pesquisa exploratória realizada através de diversas técnicas teve como foco e lócus de análise a gestão e o gerenciamento de resíduos sólidos com um paralelo entre as e conceitos existentes aplicados ao entendimento de problemas locais à extrema preocupação com a gestão dos resíduos sólidos urbanos e sustentabilidade.

\section{DESCRIÇÃO DO MUNICÍPIO}

O município de Criciúma possui $235,7 \mathrm{~km}^{2}$ e população estimada de 209.153 habitantes (IBGE, 2016), apresentando uma densidade demográfica de 816 habitantes $/ \mathrm{km}^{2}$. Localiza-se ao sul de Santa Catarina (Figura 1) na latitude $28^{\circ} 40^{\prime} 28^{\prime \prime}$ e longitude $49^{\circ} 22^{\prime} 02^{\prime}$ '. Está a uma distância de 192 km de Florianópolis e 260 km de Porto Alegre.

Figura 1 - Localização do município de Criciúma - SC

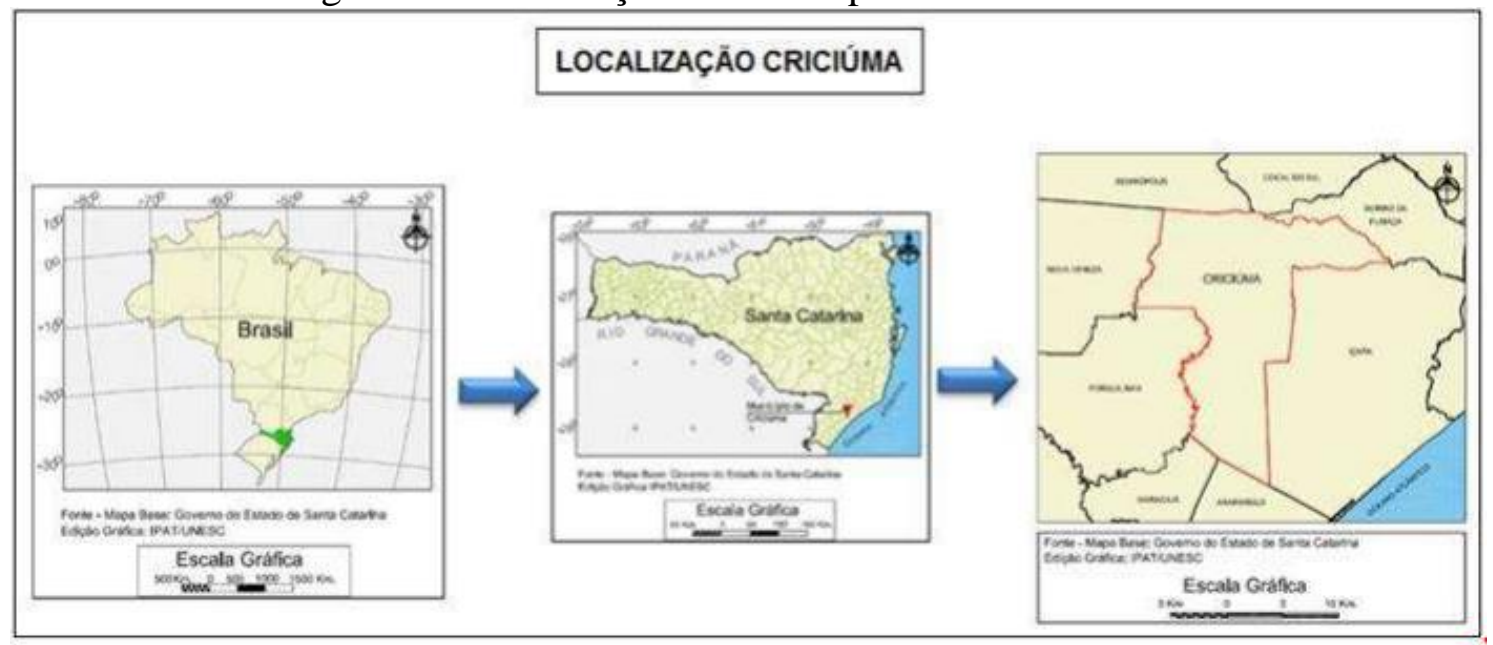

Fonte: UNESC/IPAT, 2013.

O município de Criciúma é a sede da AMREC - Associação dos Municípios da Região Carbonífera, que reúne mais nove municípios. Conta com parque industrial cerâmico, químico (tintas e vernizes), metal mecânico, além de instituições de ensino superior e diversidade de prestação de serviços e comércio, atraindo à vida urbana diariamente um 
contingente de pessoas para afazeres, estudo, compras, transações comerciais, que geram diariamente resíduos principalmente de origem domiciliar e comercial.

\section{GERAÇÃO E CARACTERIZAÇÃO DE RESÍDUOS URBANOS}

A cidade produz em média 144 t/dia, o que significa uma média individual de produção em torno de $690 \mathrm{~g} / \mathrm{hab} \cdot \mathrm{dia}^{-1}$, sendo os meses de novembro, dezembro e janeiro os de menor geração (Gráfico 1), devido ao êxodo de parte da população para praias ou viagens. Uma família de cinco pessoas em Criciúma pode gerar até 1,27 t de resíduos/ano de origem domiciliar.

Gráfico 1 - Geração per capita mensal de resíduos domésticos em Criciúma - SC.

$\left(\mathrm{Kg} /\right.$ hab.dia- $\left.^{1}\right)$

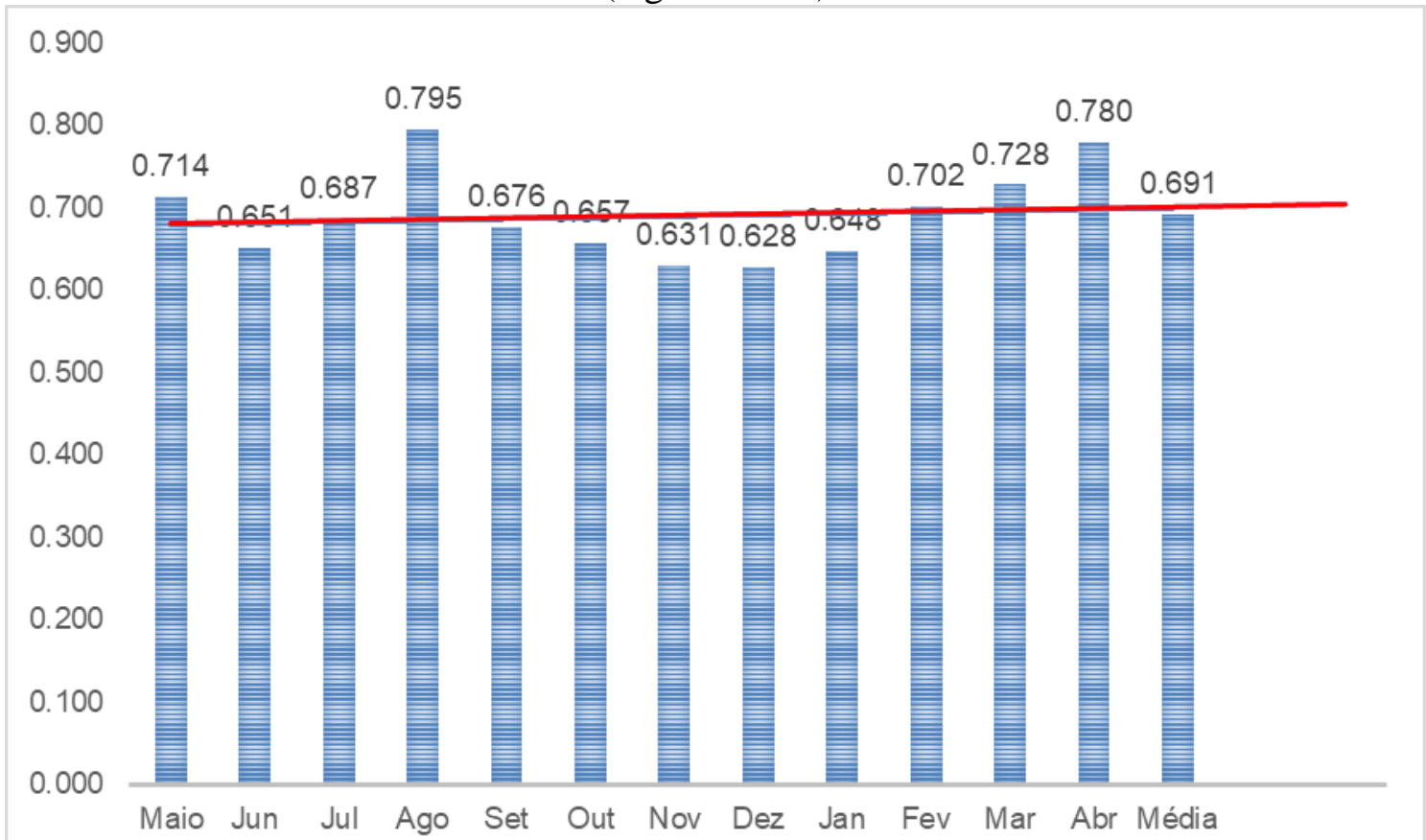

Fonte: Dados dos autores com bases em informações da empresa de coleta RACLI (Maio 2016 - Abril 2017).

O conhecimento da caracterização física dos resíduos sólidos urbanos (RSU), principalmente sua composição gravimétrica e geração total, é fundamental para a implantação de um programa de gestão e gerenciamento integrado de resíduos municipais de forma eficiente e eficaz, uma vez que permite identificar a quantidade e o potencial de materiais recicláveis, compostáveis e rejeitos. No entanto, poucos municípios brasileiros fazem a caracterização física qualitativa de seus RSU.

Os estudos que embasaram o Plano Nacional de Resíduos Sólidos apontaram uma composição média nacional de 31,9\% de resíduos secos e 51,4\% de resíduos úmidos no total dos resíduos sólidos urbanos coletados. Cada localidade tem seu quadro específico, que 
poderá ser revelado por caracterizações realizadas periodicamente, cumprindo os procedimentos das normas brasileiras.

Para estimar a quantidade dos diferentes tipos de resíduos produzidos, como resíduos orgânicos, papel e papelão, plástico, vidro etc., foram utilizados os dados da composição gravimétrica média do Brasil, que são provenientes da média de 93 estudos de caracterização física realizados entre 1995 e 2008. Deve-se chamar atenção para o fato de esses estudos nem sempre utilizarem a mesma metodologia (frequência, escolha da amostra e divisão das categorias), o que resulta numa estimativa do comportamento real da situação (MILANEZ; MASSUKADO, 2012, p. 7).

O Plano Nacional de Resíduos Sólidos realizado em 2011, após cinco audiências regionais e uma nacional, com participação de representantes da sociedade civil, setores empresariais, consultores, setor público nas três esferas de gestão, estabeleceu uma meta que era a de Redução dos Resíduos Sólidos Urbanos Secos dispostos em aterros sanitários e Inclusão de Catadores de Materiais Reutilizáveis e Recicláveis, tendo como Diretriz 1 a Redução progressiva dos resíduos recicláveis secos dispostos em aterros sanitários com base na caracterização nacional (composição gravimétrica) a ser realizada em 2013 (MILANEZ; MASSUKADO, 2012, p. 7).

O objetivo maior de um plano de gerenciamento é encontrar a solução correta para os resíduos gerados. Dessa forma, o estudo de composição gravimétrica é ferramenta fundamental para justificar a implantação de qualquer solução tecnológica no tratamento de resíduos, pois permite identificar o percentual de cada componente em relação ao peso total da amostra de material analisada.

Conforme Guadagnin e Souza (2009), a caracterização dos resíduos sólidos domiciliares, por meio da composição gravimétrica, permite identificar a quantidade e, principalmente, a qualidade dos resíduos gerados pelas residências, sendo a primeira etapa de qualquer definição posterior de gerenciamento.

Segundo Zanta et al. (2006, p. 6), "a composição gravimétrica é usada para avaliação de alternativas tecnológicas de tratamento fornecendo, juntamente com a taxa de geração, uma estimativa da quantidade gerada por cada categoria avaliada”.

De acordo com a Política Nacional de Resíduos Sólidos (Lei 12.305/10 e Decreto 7.404/2010), a União, os Estados, os Municípios e diversas empresas privadas de diferentes setores são obrigados a elaborarem Planos de Gerenciamento de Resíduos (BRASIL, 2010b; BRASIL, 2010a). 
As soluções técnicas apresentadas precisam estar baseadas no diagnóstico dos resíduos sólidos. Em se tratando de municípios, o diagnóstico dos resíduos serve também para o cálculo de dimensionamento de uma central de tratamento de resíduos, seja de reciclagem, biogás ou mesmo aterro sanitário.

Os componentes mais comuns são: matéria orgânica, metal ferroso, borracha, papel, metal não ferroso, couro, papelão, alumínio, pano/trapo, plástico rígido, vidro, madeira, ossos, plástico mole, cerâmica e agregados finos. Dessa forma, é possível identificar o aproveitamento tanto das frações recicláveis para comercialização quanto da matéria orgânica para a produção de composto orgânico (MONTEIRO et al., 2001).

No Brasil, de acordo com Guadagnin e Souza (2009), existem diversos trabalhos de determinação da composição gravimétrica dos resíduos sólidos domiciliares, os quais consideram as categorias de matéria orgânica, papel/papelão, plástico, vidro e metais. Portanto, com o conhecimento da composição gravimétrica dos resíduos é possível identificar o aproveitamento tanto das frações recicláveis para comercialização quanto da matéria orgânica para a produção de composto orgânico em compostagem aeróbica ou anaeróbica (biometanização) e destino ambientalmente correto de rejeitos para aterros sanitários (MONTEIRO et al., 2001).

O estudo gravimétrico dos resíduos sólidos urbanos tem uma grande importância tanto para a identificação do tipo de resíduo gerado de acordo com a sua qualidade e quantidade, que varia de acordo com a região, quanto para obter informações importantes em relação a ações de reciclagem que podem ser estabelecidas paralelamente à iniciativa da administração pública e, assim, bem direcionar e planejar novas ações visando minimizar a quantidade de resíduos sólidos urbanos.

Segundo Guadagnin et al. (2001), a identificação e caracterização dos constituintes de cada localidade são fundamentais na determinação da alternativa tecnológica mais adequada, desde a etapa de coleta, transporte, reaproveitamento, reciclagem até a destinação final dos rejeitos em aterros sanitários ou controlados. Dessa forma, o estudo gravimétrico é ferramenta fundamental para justificar a implantação de qualquer solução técnica ou metodológica de tratamento de resíduos.

A caracterização é a primeira atitude a ser tomada, a fim de tornar possível a segregação, o acondicionamento diferenciado, a coleta, o transporte, o tratamento e a disposição final adequados (RISSO, 1993 apud SCHNEIDER et al., 2004, p. 229).

Guadagnin et al. (2001) realizaram um estudo sobre a composição gravimétrica dos 
resíduos da região sul catarinense, abrangendo os municípios de Criciúma, Içara e Nova Veneza no período de outubro e novembro de 2000. Essa pesquisa contemplou os bairros de todas as zonas geradoras de resíduos, porém alguns setores como áreas comerciais, bares, restaurantes, hotéis, condomínios, prestadores de serviços e shoppings não foram caracterizados, ou por estarem misturados com os resíduos domiciliares ou por não serem possíveis de incluir no estudo.

A Tabela 1 apresenta os resultados da composição gravimétrica dos resíduos sólidos urbanos nos municípios de Criciúma, Içara e Nova Veneza no ano 2000 e traz um comparativo com estudos mais recentes obtidos quando da realização de proposta de concepção para coleta seletiva e elaboração do PMGIRS.

A Tabela 2 apresenta os dados de geração de resíduos sólidos urbanos coletados no período Maio 2016 - Abril 2017 pelo serviço de coleta convencional e de coleta seletiva que é realizado pela empresa RACLI. A partir dos dados obtidos, foram realizadas estimativas de geração de resíduos coletados por dia, mês, geração em $\mathrm{kg} / \mathrm{hab} \cdot \mathrm{dia}^{-1}$ e estimada a taxa de recuperação de materiais recicláveis.

Tabela 1 - Comparativo de composição gravimétrica média dos resíduos sólidos urbanos Brasil e municípios de Criciúma, Içara e Nova Veneza (2000) e Criciúma (2013, 2014, 2015)

\begin{tabular}{|c|c|c|c|c|c|c|}
\hline \multirow{2}{*}{ Resíduos } & \multirow{2}{*}{$\begin{array}{l}\text { Participação } \\
\text { Brasil }(\%)^{1}\end{array}$} & \multirow{2}{*}{$\begin{array}{l}\text { Criciúma, Içara, Nova } \\
\text { Veneza }(2001)^{2}\end{array}$} & \multicolumn{3}{|c|}{ Criciúma } & \multirow{3}{*}{ Média } \\
\hline & & & $(07 / 2013)^{3}$ & $2014^{4}$ & $2015^{4}$ & \\
\hline Número de estudos & 93 & 11 & 12 & 8 & 4 & \\
\hline Tipo de resíduos & $\%$ em peso & $\%$ em peso & \multicolumn{3}{|c|}{$\%$ em peso } & $\begin{array}{l}\% \mathrm{em} \\
\text { peso }\end{array}$ \\
\hline Material reciclável & 31,9 & 43,55 & 46,4 & 43,19 & 40,90 & 43,50 \\
\hline Metais & 2,9 & 3,25 & 2,23 & 2,62 & 2,59 & 2,48 \\
\hline Aço & 2,3 & - & - & - & - & - \\
\hline Alumínio & 0,6 & - & - & - & - & - \\
\hline $\begin{array}{l}\text { Papel, papelão e } \\
\text { Multicamada }\end{array}$ & 13,1 & 21,06 & 18,28 & 12,04 & 10,69 & 13,67 \\
\hline Plástico total & 13,5 & 17,13 & 22,99 & 18,61 & 22,56 & 21,39 \\
\hline Plástico filme & 8,9 & - & 13,75 & 12,11 & 13,69 & 13,18 \\
\hline Plástico rígido & 4,6 & - & 9,24 & 6,50 & 8,87 & 8,20 \\
\hline Vidro & 2,4 & 2,11 & 2,90 & 9,92 & 5,06 & 5,96 \\
\hline Matéria orgânica & 51,4 & 45,22 & 27,92 & 38,55 & 33,13 & 33,20 \\
\hline Outros/rejeitos & 16,7 & 11,23 & 25,68 & 18,26 & 25,96 & 23,30 \\
\hline Total & 100 & 100 & 100 & 100 & 100 & 100 \\
\hline
\end{tabular}

Fonte: BRASIL, 2012b, p. $36^{1}$; GUADAGNIN et al. $2001^{2}$ UNESC/IPAT, $2013^{3}$, p. $160^{3}$; SC ENGENHARIA E GEOTECNOLOGIA, $2016^{4}$, p. 212.

Em Criciúma, 33,21\% dos resíduos gerados são compostos por matéria orgânica, 23\% por rejeito e o restante, $43,49 \%$, são materiais secos que poderiam ser reciclados e apenas 23,3 $\%$ cerca de $1 / 4$ são rejeitos, que, conforme preconiza a Política Nacional de Resíduos Sólidos, 
deveria ser disposta de forma ambientalmente adequada em aterros sanitários (Gráfico 2). No entanto, atualmente uma fração pequena dos materiais recicláveis é coletada, cerca de apenas 2,03\% (Gráfico 3) (Tabela 2) e triados por duas organizações de catadores, a Associação de Criciumense de Catadores (ACRICA) e a Cooperativa de Trabalhadores em Materiais Recicláveis (CTMAR), com retorno à cadeia de reciclagem tendo como principal motivo a baixa participação da população na separação na fonte, a descontinuidade de estratégias de mobilização, sensibilização e educação ambiental, o que reduz a eficiência na coleta seletiva.

Os espaços disponibilizados tanto para a CTMAR quanto para a ACRICA são precários e se reportam às condições e estruturas operacionais, segundo Eigenheer, Ferreira e Adler (2005), que eram utilizadas no final do século XIX em cidades como Nova Iorque, Munique ou Budapeste. As condições de trabalho associado à qualidade do material recebido, pela baixa eficiência na coleta seletiva e no pouco envolvimento da população com o gerenciamento de resíduos sólidos, fazem com que os catadores e catadoras apenas transfiram a antiga condição de trabalho em lixões a céu aberto comum em Santa Catarina até meados da década de 2000 para a condição de "lixões cobertos" nos galpões improvisados de separação e triagem disponibilizados para empreendimentos organizados quer em associações ou cooperativas. (Figura 2).

Figura 1 - Usinas de Triagem A) Nova Iorque, 1897; B) ACRICA, Criciúma, 2014. C) Esteira de Triagem, Budapeste, cerca de 1900. D) Esteira de Triagem. CTMAR, Criciúma, 2014

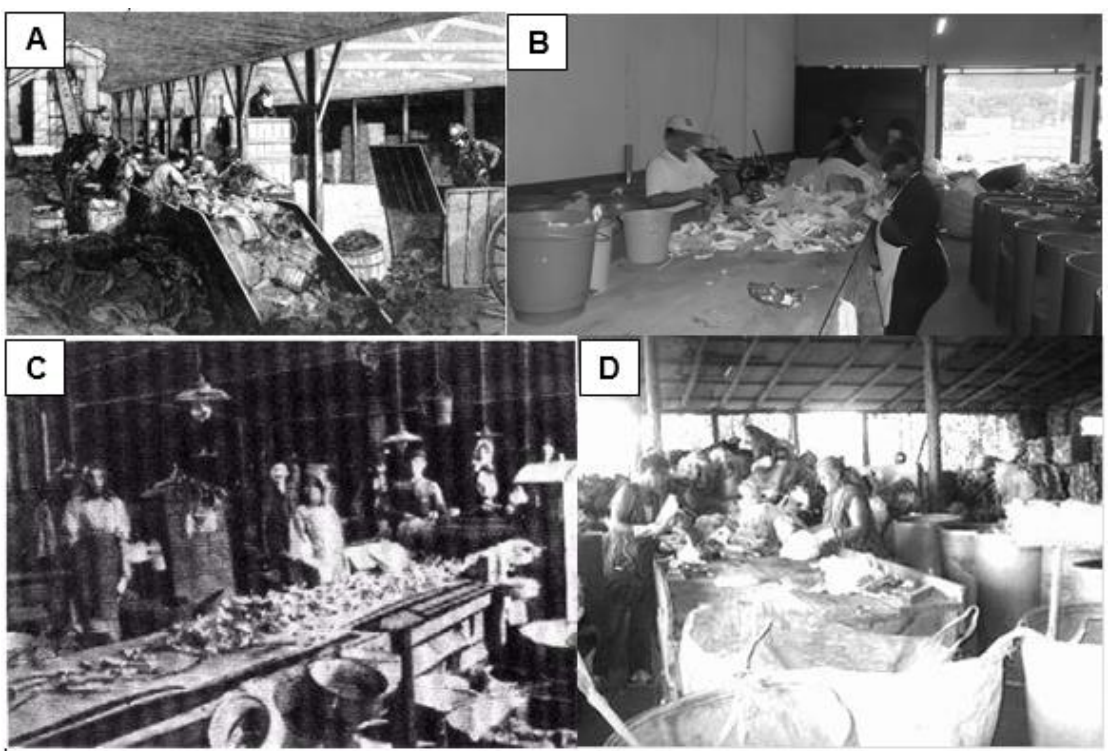

Fonte: A) Eigenheer, Ferreira e Adler (2005, p. 31); C) Eigenheer, Ferreira e Adler 2005, p. 38; B; D; PAVAN, 2014 , p. 55. 
Gráfico 2 - Gráfico qualitativo da geração de resíduos domiciliares de Criciúma - SC

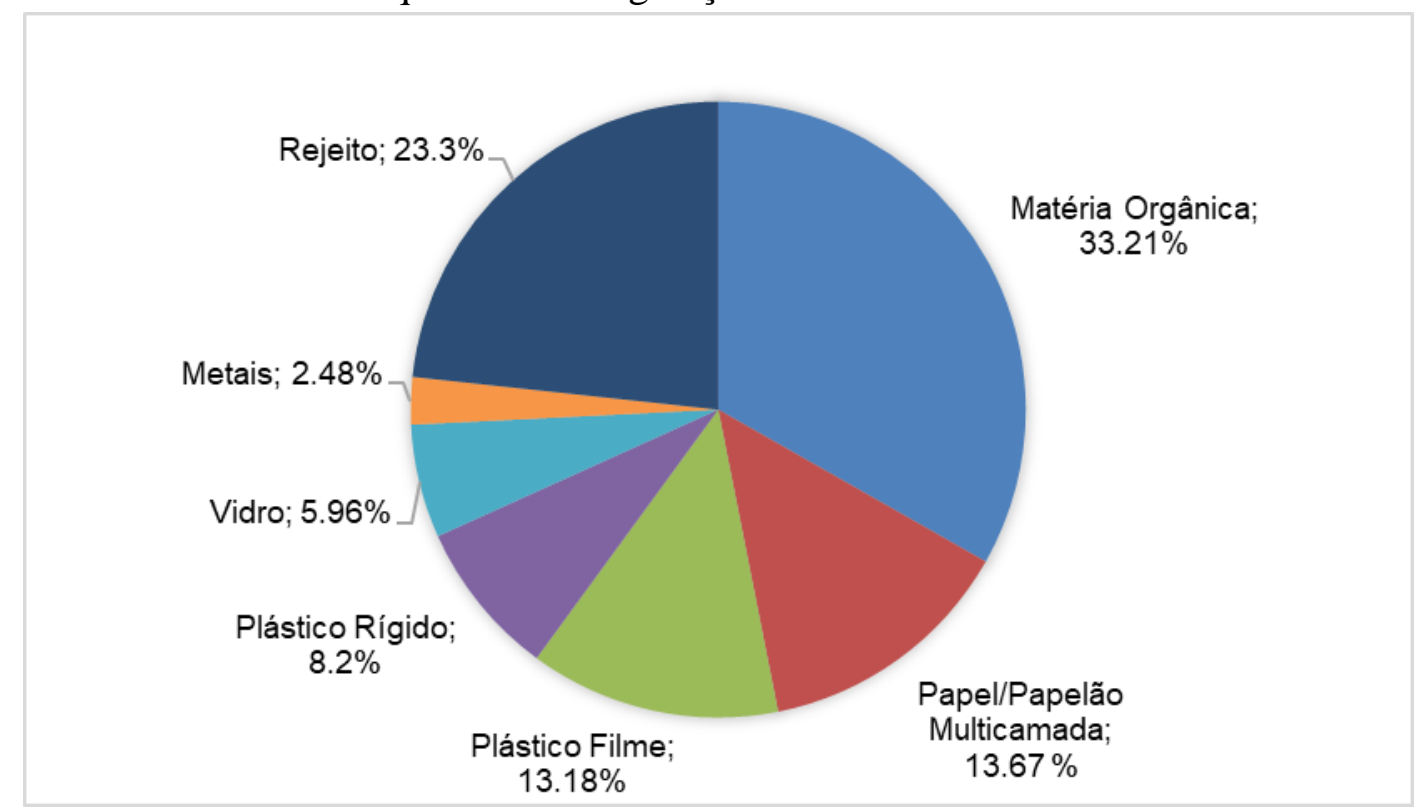

Fonte: Médias dos estudos de composição Gravimétrica 2013-2015. UNESC/IPAT, 2013, p. 160; SC Engenharia e Geotecnologia, 2016, p. 212.

Tabela 2 - Geração de resíduos sólidos urbanos. Coleta convencional e coleta seletiva. Indicadores de geração per capita e taxa de eficiência de recuperação de materiais recicláveis em Criciúma - SC (Maio 2016 - Abril 2017)

\begin{tabular}{|c|c|c|c|c|c|c|}
\hline Meses & $\begin{array}{c}\text { Coleta } \\
\text { Convencional } \\
(\mathrm{T} / \mathrm{mês})\end{array}$ & $\begin{array}{l}\text { Coleta } \\
\text { Seletiva } \\
\mathrm{T}(/ \mathrm{mês})\end{array}$ & $\begin{array}{l}\text { Geração } \\
\text { RSD } \\
\text { (T/mês) }\end{array}$ & $\begin{array}{c}\text { Geração } \\
\text { média (T/dia) }\end{array}$ & $\begin{array}{c}\text { Geração Per } \\
\text { Capita } \\
\left(\mathrm{Kg} / \mathrm{Hab} \text { dia }^{-1}\right) \\
\end{array}$ & $\begin{array}{l}\text { Taxa de } \\
\text { Recuperação de } \\
\text { Recicláveis }(\%)\end{array}$ \\
\hline Maio & $4.599,73$ & 29,94 & $4.629,67$ & 149,34 & 0,714 & 0,65 \\
\hline Jun & $3.986,63$ & 95,11 & $4.081,74$ & 136,06 & 0,651 & 2,33 \\
\hline Jul & $4.351,40$ & 102,42 & $4.453,82$ & 143,67 & 0,687 & 2,30 \\
\hline Ago & $5.052,08$ & 99,6 & $5.151,68$ & 166,18 & 0,795 & 1,93 \\
\hline Set & $4.144,37$ & 95,17 & $4.239,54$ & 141,32 & 0,676 & 2,24 \\
\hline Out & $4.018,44$ & 103,89 & $4.122,33$ & 137,41 & 0,657 & 2,52 \\
\hline Nov & $3.865,05$ & 92,16 & $3.957,21$ & 131,91 & 0,631 & 2,33 \\
\hline Dez & $3.950,11$ & 124,22 & $4.074,33$ & 131,43 & 0,628 & 3,05 \\
\hline Jan & $4.111,07$ & 90,94 & $4.202,01$ & 135,55 & 0,648 & 2,16 \\
\hline $\mathrm{Fev}$ & $4.022,81$ & 88,17 & $4.110,98$ & 146,82 & 0,702 & 2,14 \\
\hline Mar & $4.624,15$ & 95,99 & $4.720,14$ & 152,26 & 0,728 & 2,03 \\
\hline Abr & $4.812,65$ & 83,16 & $4.895,81$ & 163,19 & 0,78 & 1,70 \\
\hline Média & $4.294,87$ & 91,73 & $4.386,61$ & 144,6 & 0,691 & 2,09 \\
\hline
\end{tabular}


Gráfico 3 - Coleta dos resíduos sólidos domiciliares (convencional/seletiva), Maio 2016 Abril 2017
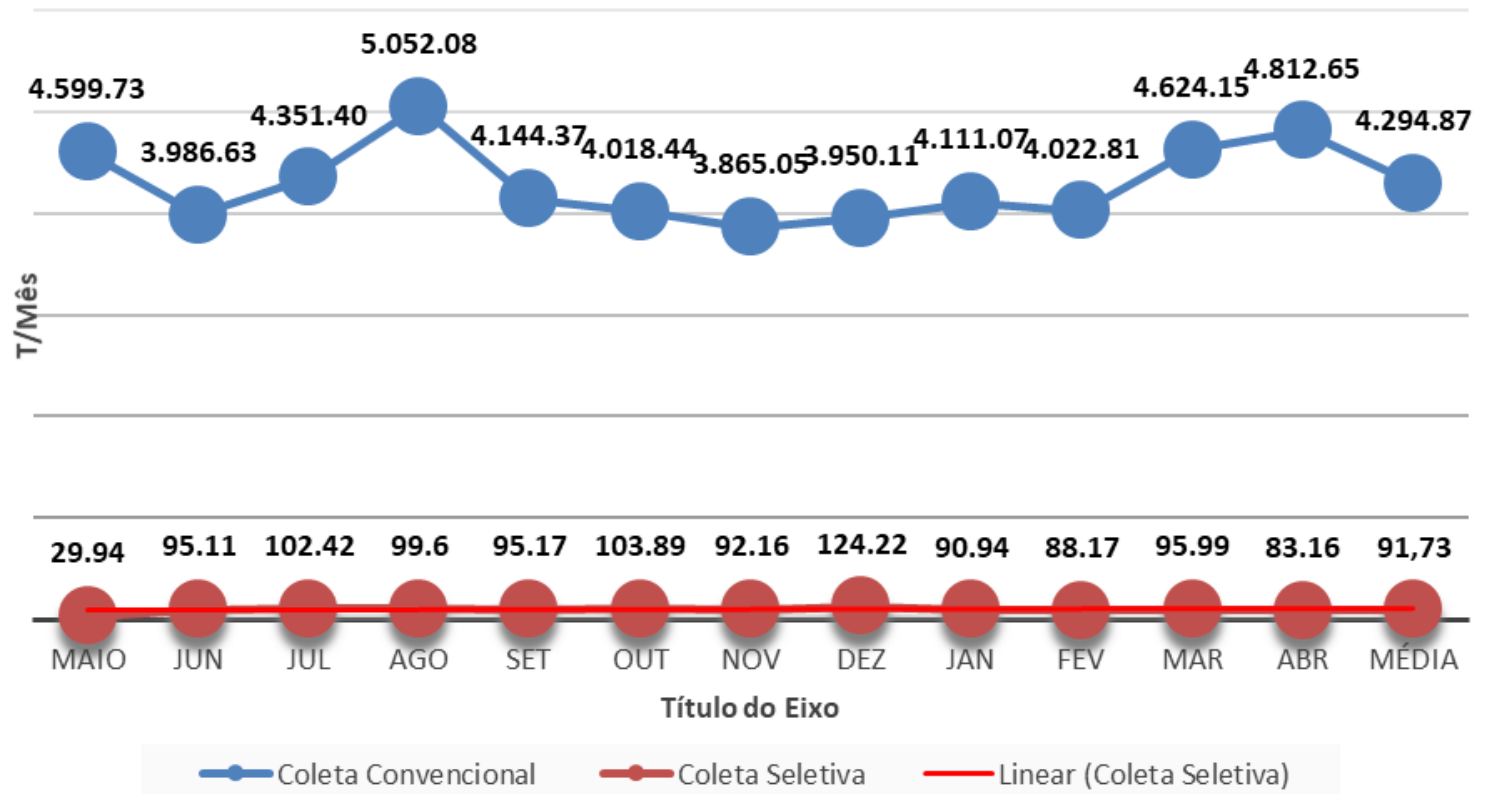

Fonte: Adaptado de RACLI (2017). Informação verbal ${ }^{1}$.

\section{GESTÃO E GERENCIAMENTO DOS RESÍDUOS SÓLIDOS URBANOS}

Para a Política Nacional de Resíduos Sólidos, em seu art. $3^{\circ}$, inciso X, o gerenciamento de resíduos sólidos é definido como:

[...] o conjunto de ações exercidas, direta ou indiretamente, nas etapas de coleta, transporte, transbordo, tratamento e destinação final ambientalmente adequada dos resíduos sólidos e disposição final ambientalmente adequada dos rejeitos, de acordo com plano municipal de gestão integrada de resíduos sólidos ou com plano de gerenciamento de resíduos sólidos (BRASIL, 2010b).

Nessa mesma lei, em seu art. $3^{\circ}$, inciso XI, o termo gestão integrada de resíduos sólidos consiste em

[...] conjunto de ações voltadas para a busca de soluções para os resíduos sólidos, de forma a considerar as dimensões política, econômica, ambiental, cultural e social, com controle social e sob a premissa do desenvolvimento sustentável (BRASIL, 2010b).

\footnotetext{
${ }^{1}$ RACLI. Racli Ambiental RacSaneamento - Ionice Vefago Dados da quantidade de resíduos da coleta de Criciúma. [mensagem pessoal] Mensagem recebida por: <mrg@ unesc.net>. Acesso em: 2 maio 2017.
} 
O gerenciamento de resíduos sólidos abrange diversos fatores, envolvendo a logística e operação do sistema. Os fatores administrativos, gerenciais, econômicos, ambientais e de desempenho devem ser analisados no gerenciamento dos resíduos sólidos, sendo esses fatores relacionados com a redução, prevenção, segregação, reutilização, acondicionamento, coleta, transporte, disposição e destinação final dos resíduos (LIMA, 2001).

O gerenciamento, composto por ações de coleta, transporte, transbordo, tratamento e destinação final ambientalmente adequada dos resíduos sólidos (unidades de reciclagem, por exemplo) e disposição final adequada dos rejeitos (aterros sanitários, de inertes ou para rejeitos perigosos) são ações de responsabilidade dos geradores, que podem desenvolvê-las direta ou indiretamente (RIBEIRO; AMARAL, 2013, p. 42).

O gerenciamento é o componente operacional da gestão de resíduos sólidos, e o gerenciamento integrado é feito ao se considerar uma variedade de alternativas para atingir, entre outros propósitos, a minimização dos resíduos sólidos.

Já a gestão integrada, de acordo com Cândido et al.,

[...] é um conjunto articulado de ações normativas, operacionais, financeiras e de planejamento que uma administração municipal deve desenvolver com base em critérios sanitários, ambientais e econômicos, para coletar, transportar, segregar, tratar e dispor o lixo (2009, p. 12).

A gestão de resíduos sólidos é um crescente desafio para a sociedade atual, especialmente para a administração pública, em razão da quantidade e da diversidade de resíduos, do crescimento populacional e do consumo, da expansão de áreas urbanas e da cultura histórica de aplicação de recursos insuficientes para a gestão ambientalmente adequada de resíduos.

A Política Nacional de Resíduos Sólidos estabelece uma série de princípios (Art. $7^{\circ}$, inciso II) e diretrizes (art. $9^{\circ}$ ) com direcionamento de ações para a gestão e o gerenciamento de resíduos sólidos, com uma primazia sequencial: "não geração, redução, reutilização, reciclagem e tratamento dos resíduos sólidos, bem como disposição final ambientalmente adequada dos rejeitos" (BRASIL, 2010).

A Figura 3 demonstra a hierarquia na gestão dos resíduos sólidos no Brasil. Dessa forma, antes de pensar na melhor forma para dispor os resíduos gerados ou melhorar a coleta seletiva, é necessário conscientizar sobre a redução ou não geração de resíduos. 


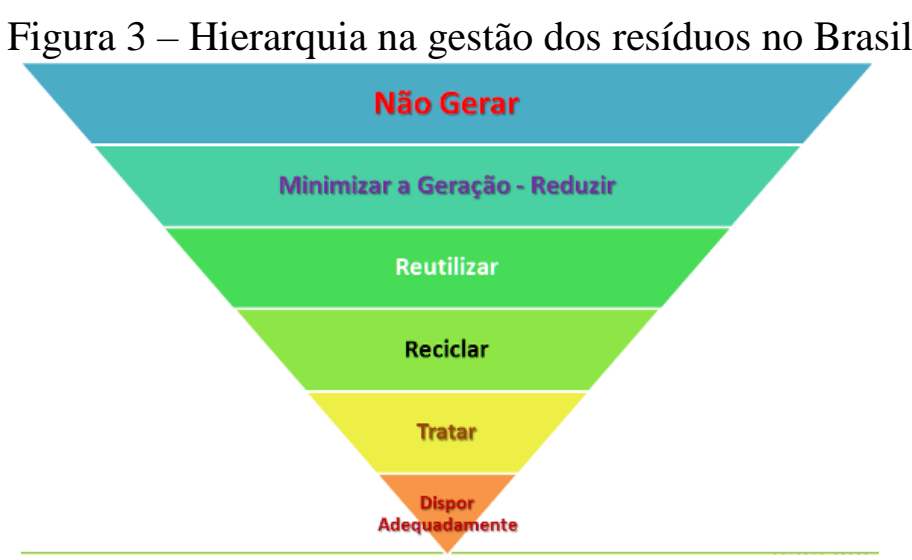

Fonte: Adaptado de Brasil (2010b).

Dentre as diversas causas da inadequada gestão dos resíduos sólidos na maioria dos municípios brasileiros, Moraes e Borja (2009) destacam:

a) inexistência de uma política pública de resíduos sólidos;

b) limitações de ordem financeira, como orçamentos inadequados, fluxo de caixas desequilibrados, taxas desatualizadas quando existem, arrecadação insuficiente e inexistência de linha de crédito específica;

C) pouca capacidade institucional;

d) deficiência na capacitação técnica e profissional do gari ao engenheiro-chefe;

e) descontinuidade política e administrativa;

f) uso de tecnologias inadequadas às realidades institucional, operacional, à disponibilidade de recursos humanos e financeiros e aos aspectos de ordem sociocultural;

g) falta de programas de educação ambiental;

h) pouco envolvimento da sociedade com a problemática dos resíduos sólidos;

i) ausência de controle ambiental.

Para os resíduos sólidos domiciliares, "a prestação de serviços, característicos do gerenciamento, é de responsabilidade da municipalidade, podendo ser exercida direta ou indiretamente, mas sempre de acordo com o previsto no plano municipal de gestão integrada" (RIBEIRO; AMARAL, 2013, p. 43).

Segundo Ribeiro e Amaral:

Cada tipo de resíduo, em razão de suas características, exige um modelo de gerenciamento adequado, visando não só sua coleta, mais transporte, tratamento, 
destinação e sua disposição final com a finalidade de minimizar problemas ambientais, incluindo os impactos a saúde pública (2013, p. 45).

De acordo com Zanta e Ferreira (2003), o gerenciamento dos resíduos sólidos urbanos deve ser integrado com atividades compatíveis com os demais sistemas do saneamento ambiental, compreendendo etapas desde a não geração até a disposição final.

Conforme Ribeiro e Amaral (2013, p. 45), “o gerenciamento não envolve apenas questões políticas, mais principalmente questões técnicas e operacionais de planejamento, implantação, execução e monitoramento, fundado em critérios ambientais, sanitários e econômicos".

A solução dos problemas dos resíduos sólidos e limpeza pública deveriam constituir uma das preocupações em todos os níveis de governo, destacando a atuação do governo municipal, seja pelas razões sanitárias, seja pelo reflexo estético na beleza de uma cidade limpa (PHILIPPI JR; AGUIAR, 2005).

Gerenciar os resíduos sólidos e sua disposição envolve diversos aspectos, como mercado, legislação, disponibilidade de aterros, controle de poluição, conscientização e participação da comunidade, além de outros fatores (MARIGA, 2010, p. 50).

Segundo Zanta (2006), é de responsabilidade do poder público municipal a gestão dos serviços de limpeza pública e manejo dos resíduos sólidos, compreendendo os resíduos de origem doméstica ou de varrição e limpeza pública.

O gerenciamento dos resíduos municipais deve começar pelo conhecimento das suas características, pois vários fatores podem influenciar qualitativamente e quantitativamente, como número de habitantes, poder aquisitivo da população, condições climáticas predominantes, hábitos e costumes da população e nível educacional (GRIPPI, 2001).

De acordo com Besen:

\begin{abstract}
A implementação da PNRS representa um momento favorável para romper com antigas lógicas e práticas prevalecentes na área de resíduos sólidos que priorizem a coleta, transporte, tratamento e disposição final de resíduos e construir sistemas de gestão de resíduos sólidos mais sustentáveis, assim como apoiar a estruturação de uma cadeia produtiva e de valor de reciclagem mais justa com os catadores de matérias recicláveis que estão em sua base (2012, p. 411)
\end{abstract}

“O principal desafio na gestão dos resíduos é a garantia de uma gestão integrada e sustentável. Isso implica articular as dimensões de sustentabilidade econômica, ambiental, social e institucional” (BESEN, 2014, p. 266). 
A coleta seletiva, os sistemas de logística reversa, o incentivo à criação e ao desenvolvimento de cooperativas ou outras formas de associação de catadores, a pesquisa científica e tecnológica, a educação ambiental é instituída como instrumentos na PNRS.

A ausência de planejamento e de políticas setoriais que priorizem ações integradas evidencia a necessidade de envolver mais os diversos setores da sociedade na resolução dos problemas relacionados com o meio ambiente e que são gerados por ela mesma (MARIGA, 2010, p. 51).

Os municípios são os principais responsáveis pela realização da destinação e disposição final dos resíduos sólidos, necessitando de soluções ambientais corretas na maioria dos municípios brasileiros (MARIGA, 2010).

É preciso incentivar a redução da geração e o aumento do aproveitamento dos resíduos sólidos, o que requer o estabelecimento de mecanismos que extrapolam as competências municipais e estaduais, por exemplo, a atribuição de responsabilidade aos fabricantes pelo ciclo total do produto, incluindo a obrigação de recolhimento após o uso pelo consumidor, ou tributação diferenciada por tipo de produto (JURAS, 2000, p. 5).

\begin{abstract}
A prefeitura aparece como o protagonista do sistema ao articular a função dos diversos agentes por meio do estabelecimento de parcerias e convênios. Os grandes geradores devem ser responsabilizados para destinar adequadamente seus rejeitos. A população tem um papel fundamental, garantindo a separação adequada dos materiais recicláveis. Por fim, a gestão integrada e compartilhada reconhece o papel dos catadores como atores centrais do sistema. (DEMAJOROVIC; LIMA, 2013, p. $62)$.
\end{abstract}

\title{
CADEIA DE ELIMINAÇÃO DOS RESÍDUOS SÓLIDOS
}

A cadeia de eliminação dos resíduos sólidos inicia pelo acondicionamento na fonte geradora, posterior coleta, transporte, tratamento e encaminhamento ao local de disposição final. Quando submetidos à reciclagem ou compostagem, os resíduos sólidos podem ser potencialmente reintegrados ao meio ambiente.

\section{ACONDICIONAMENTO}

$\mathrm{O}$ acondicionamento adequado depende das embalagens empregadas, as quais devem conferir bom desempenho e atender aos requisitos de acondicionamento local e estático dos resíduos. Tanto o emprego de um ou mais recipientes apropriados quanto a colocação desses em frente às residências ou nos pontos de coleta na data e hora estabelecida estão a cargo do usuário (PARRA et al, 2000 e MONTEIRO, 2001). 
Segundo Monteiro (2001), o gerenciamento na fonte geradora consiste no acondicionamento e tratamento dos resíduos no interior da unidade residencial, comercial ou industrial, desde o momento de geração até a apresentação ao pessoal de coleta. Quando os resíduos não são acondicionados adequadamente, além do comprometimento da eficiência das etapas consecutivas de coleta e transporte, podem ser desencadeados graves problemas sanitários.

Os equipamentos mais utilizados, segundo Martinho e Gonçalves (2000) e Parra et al. (2000), são os sacos plásticos, caixas empilháveis, baldes ou contentores de pequena dimensão.

Em Criciúma, os resíduos são acondicionados em sacolas plásticas, predominando a colocação e sacos de supermercado em detrimento aos sacos de lixo, armazenados nas lixeiras sem padronização localizadas na testada do imóvel.

\section{SISTEMA DE COLETA E TRANSPORTE}

A ABNT em sua NBR 12.980 (1993) determina os diferentes tipos de serviço de coleta de resíduos. Define como coleta domiciliar ou convencional aquela destinada ao recolhimento dos resíduos provenientes das residências, estabelecimentos comerciais e indústrias, diferentemente da coleta de resíduos oriundos da varrição de ruas, praças e calçadas, bem como da coleta de feiras e praias, e por fim, da coleta de resíduos de serviços de saúde.

De acordo com Monteiro (2001), o sistema de coleta e transporte consiste no conjunto de operações de carga, transporte e descarga. Inicia com a coleta dos resíduos na parte externa das edificações até a descarga pelos veículos coletores no local de tratamento ou disposição final.

Segundo Parra et al. (2000), o sistema de coleta e transporte dos resíduos sólidos deve ser planejado com qualidade e produtividade, a baixo custo. O planejamento do transporte deve ser feito rota por rota. Para tanto, são informações relevantes os fluxos nas diversas ligações da rede, o nível de serviço atual e o desejado, características ou parâmetros sobre a carga (peso, volume, dimensões da carga e do veículo, periculosidade) e tipos de equipamentos disponíveis.

Na opinião de Monteiro (2001), a coleta deve ser realizada por veículos especialmente construídos para essa finalidade. No caso de estações de transferência ou transbordo, tais são necessárias quando o deslocamento de transporte ao lugar de tratamento é superior a 15- 20 
km ou são produzidas quantidades consideráveis. A fase de coleta e transporte dispende entre 60 e $80 \%$ dos custos globais do gerenciamento dos resíduos.

$\mathrm{Na}$ cidade de Criciúma, a coleta convencional é realizada da seguinte forma: os caminhões compactadores coletores e as equipes de coleta partem da garagem da RACLI, com destino aos seus respectivos roteiros de coleta. Esses roteiros são monitorados por software de acompanhamento on-line com GPS.

Em cada roteiro de coleta, há um motorista e três garis realizando os serviços de coleta de resíduos domiciliares. Um gari vai à frente do caminhão coletando os resíduos das lixeiras de residências unifamiliares ou multifamiliares e comerciais, realizando o amontoamento em alguns pontos das ruas. Posteriormente, o caminhão coletor estaciona ao lado do ponto de amontoamento e os resíduos são coletados pelos outros dois garis.

Após a realização da coleta convencional no bairro, ou após atingir o limite máximo de capacidade do caminhão, o veículo segue para o aterro sanitário de propriedade da empresa da RAC Saneamento, localizado na Marginal da BR 101, no município de Içara/SC. O tempo despendido para a realização das descargas no aterro sanitário, incluindo o deslocamento de ida e volta desde o roteiro de coleta, é em média de uma hora e meia. Nesse local, ocorre a pesagem dos resíduos, em balança rodoviária com capacidade de 80 toneladas.

\section{TRATAMENTO E DISPOSIÇÃO FINAL DOS RESÍDUOS SÓLIDOS}

De acordo com Monteiro (2001), entende-se por tratamento e disposição de resíduos o conjunto de operações destinadas à sua eliminação ou reaproveitamento. Na opinião do autor, os sistemas mais comumente empregados são o aterro sanitário, a incineração, a reciclagem e a compostagem. Embora o lixão represente ainda a forma de disposição final predominante no país, os vazadouros a céu aberto representam somente o abandono do lixo.

Martinho e Gonçalves (2000) afirmam que o confinamento é a operação terminal de todo o sistema de gestão dos resíduos sólidos e pode assumir diversas modalidades. Os autores salientam que os esforços de redução, reutilização, reciclagem e incineração podem minimizar a quantidade de resíduos. Contudo, sempre permanecem residuais que necessitam ser corretamente destinados.

Lima (2001) assegura que há várias formas de tratamento e cita as principais: incineração, compostagem, aterro sanitário, aterro controlado e sistemas de tratamento de líquidos percolados (chorume). 
A disposição final de resíduos sólidos urbanos de Criciúma ocorre em aterro sanitário que opera de acordo com os requisitos técnicos e ambientais estabelecidos em normas técnicas e regras ambientais. A vida útil dele poderia ser ampliada caso os municípios que o utilizam para deposição de resíduos sólidos implementassem os princípios e diretrizes estabelecidos pela Lei 12305/2010.

O município de Criciúma, com a adoção das ações e metas estabelecidas no Plano Municipal de Resíduos Sólidos elaborado entre 2015 e 2016, pode, mediante planejamento e práticas continuadas de gerenciamento, reduzir a deposição em até $3 / 4$ do volume de resíduos desde que se adotem rotas tecnológicas que valorizem os materiais recicláveis e também a fração orgânica com a adoção de melhorias e ampliação da coleta seletiva de caráter solidário e inclusivo e com a implementação de unidades de tratamento dos resíduos orgânicos em processos de compostagem aeróbica.

\section{RECICLAGEM E COMPOSTAGEM,}

Conforme Monteiro et al. (2001), entre as alternativas para o tratamento dos resíduos sólidos urbanos a reciclagem tem despertado o maior interesse na população, sobretudo pelo seu forte apelo ambiental. Os benefícios dessa forma de tratamento representam a economia de matérias-primas não renováveis e de energia nos processos produtivos, bem como o aumento da vida útil dos aterros sanitários. Monteiro (2001) entende como um processo que tem como objetivo a recuperação de forma direta ou indireta dos constituintes encontrados nos resíduos urbanos. O processo de reciclagem ocorre a partir da separação dos componentes para sua recuperação direta, ou seja, da coleta seletiva.

Monteiro (2001) afirma que a compostagem pode ocorrer de forma aeróbia ou anaeróbia. A decomposição ocorre de forma natural, ao ar livre, ou acelerada em digestores. O tempo de duração é de três meses e 45 dias, respectivamente. O produto obtido é uma substância de cor marrom escura, denominado composto ou húmus. A compostagem compreende o processo biológico de decomposição da matéria orgânica contida em restos de origem animal ou vegetal. O produto final pode ser aplicado ao solo para melhor suas características, sem quaisquer riscos ao meio ambiente.

Quanto às vantagens desse processo, citam-se a economia de aterro, o aproveitamento agrícola da matéria orgânica e a reciclagem de nutrientes para o solo, além de ser ambientalmente seguro, com reduzido impacto ambiental (LIMA, 2001; MONTEIRO et al., 2001). 
Segundo Monteiro (2001), consiste na colocação dos resíduos sobre uma área, espalhando-os em camadas pouco espessas, compactando-os para redução do volume e cobrindo-os diariamente para minimizar os riscos de poluição ambiental. Geralmente, localizam-se afastados de núcleos populacionais. Da mesma forma, Consoni et al. (2000) concordam que o aterro sanitário permite um confinamento seguro no que se refere ao controle da poluição ambiental e proteção à saúde pública.

\section{CONSIDERAÇÕES FINAIS}

A definição de ações e estratégias de gestão e gerenciamento de resíduos sólidos no presente devem levar em consideração o cumprimento dos princípios e das diretrizes da Política Nacional de Resíduos Sólidos, conforme a Lei n. 12.305/2010. Para a consolidação de políticas públicas, é necessário o permanente controle social na efetivação e na execução do que foi planejado no Plano Municipal de Resíduos Sólidos. Alguns requisitos essenciais são necessários e devem ser adotados na melhoria do gerenciamento de resíduos em Criciúma, podendo-se enumerar:
a) educação ambiental continuada e permanente;
b) mobilização e envolvimento social;
c) redução do consumo;
d) consumo sustentável;
e) consumo responsável;
f) separação na fonte geradora;
g) acondicionamento correto;
h) coleta seletiva;
i) pontos de entrega voluntária;
j) inclusão social produtiva de catadoras e catadores.

Esses requisitos necessitam do acompanhamento de equipes técnicas multidisciplinares para melhor gestão e gerenciamento de resíduos sólidos com avaliação do sistema de gestão ambiental integrada de resíduos sólidos através do Índice de Condição da Gestão de Resíduos (ICGR) no município para avaliar o desempenho dos serviços municipais de limpeza urbana através da busca de dados a respeito da sua eficiência sanitária, 
operacional, econômica, financeira e da possibilidade de indução de desequilíbrios ambientais com a utilização de indicadores de sustentabilidade.

A gestão integrada e sustentável de Resíduos Sólidos Urbanos em Criciúma - SC necessita de uma estrutura básica que permita selecionar tecnologias apropriadas ao contexto local o desenvolvimento de um sistema com eficiência sanitária, operacional, econômica, financeira e sustentável de resíduos urbanos.

\section{REFERÊNCIAS}

ABNT. NBR 12980: Coleta e acondicionamento de Resíduos Sólidos Urbanos: terminologia. Rio de Janeiro: ABNT, 1993.

BENSEN, Gina Rizpah. Coleta Seletiva e organizações de catadores de materiais recicláveis. In: TONETO JÚNIOR, Rudinei; SAIANI, Carlos; DOURADO, Juscelino. (Org.). Resíduos sólidos no Brasil. Baureri - SP: Manole, 2014. p. 240 - 277.

BESEN, Gina Rizpah. A Questão da Coleta Seletiva Formal. In: JARDIM, Arnaldo; YOSHIDA, Consuelo; MACHADO FILHO, José Valverde (org.). Política Nacional, Gestão e Gerenciamento de Resíduos Sólidos. Barueri- SP: Manole, p. 389 - 474, 2012. (Coleção Ambiental).

BRASIL. Decreto-lei n. 7.404, de 23 de dezembro de 2010. Regulamenta a Lei n. 12.305, de 2 de agosto de 2010, que institui a Política Nacional de Resíduos Sólidos, cria o Comitê Interministerial da Política Nacional de Resíduos Sólidos e o Comitê Orientador para a Implantação dos Sistemas de Logística Reversa, e dá outras providências. Diário Oficial da União. Brasília, 16 mar 2017.

BRASIL. Lei n. 12.305, de 02 de agosto de 2010b. Institui a Política Nacional de Resíduos Sólidos; altera a Lei n⿳0 9.605, de 12 de fevereiro de 1998; e dá outras providências.

Disponível em: <http://www.planalto.gov.br/ccivil_03/_ato2007-2010/2010/lei/112305.htm>. Acesso em: 04 ago. 2017.

BRASIL. Ministério do Meio Ambiente. Plano Nacional de Resíduos Sólidos - Versão pós Audiências e Consulta Pública para Conselhos Nacionais. Brasília: MMA, 2012b. 104 p.

CÂNDIDO, Carla Valéria Lima et al. Plano de Gerenciamento Integrado de Coleta

Seletiva - PGICS. Belo Horizonte: Fundação Estadual do Meio Ambiente: Fundação Israel Pinheiro. 2009. 72 p. Disponível em:

<http://www.feam.br/images/stories/minas_sem_lixoes/2010/coletaseletiva.pdf >. Acesso em: 16 jun. 2017.

CONSONI, Ângelo José; SILVA, Isabel Cristina da; GIMENEZ FILHO, Antônio. Disposição final do lixo. In. D'ALMEIDA, Maria Luiza Otero de; VILHENA, André. (Coord). Lixo municipal: manual de gerenciamento integrado. São Paulo: Instituto de Pesquisas Tecnológicas (IPT) e Compromisso Empresarial para Reciclagem (CEMPRE), 2000. p. 251290. 
DEMAJOROVIC, Jacques; LIMA, Márcia. Cadeia de reciclagem: um olhar para os catadores. São Paulo: SENAC, 2013. 155 p.

EIGENHEER, Emílio; FERREIRA, João Alberto; ADLER, Roberto Rinder.

Reciclagem: mito e realidade. Rio de Janeiro: In-Folio, 2005. 72 p.

GRIPPI, Sidney. Lixo: reciclagem e sua história. Rio de Janeiro: Interciência, 2001. 134 p. GUADAGNIN, Mário Ricardo et al. Classificação, Determinação e análise da composição gravimétrica dos resíduos sólidos urbanos dos municípios de criciúma, Içara e Nova Veneza, do Estado de Santa Catarina - Brasil. Revista de Tecnologia e Ambiente, Criciúma, v. 7, n. 2, p.39-61, jul./dez. 2001.

GUADAGNIN, Mario Ricardo; SOUZA, Gláucia Cardoso de. Caracterização quantitativa e qualitativa dos resíduos sólidos domiciliares: método de quarteamento na definição da composição gravimétrica em Cocal do Sul - SC. In: SEMINÁRIO REGIONAL SUL DE RESÍDUOS SÓLIDOS, 3. 2009. Anais... Caxias do Sul: ABES-UCS, 2009. 10 p.

JURAS, Ilidia da A. G. Martins. Publicação eletrônica em consultoria legislativa da câmera dos deputados. Legislação sobre reciclagem de lixo. Brasília: Câmara dos Deputados Biblioteca Digital da Câmara dos Deputados. Cengro de Documentação e Informação dez. 2000. Disponível em:

<http://bd.camara.gov.br/bd/bitstream/handle/bdcamara/1028/legislacao_lixo_juras.pdf?seque nce=4.> Acesso em 10 jun. 2017.

LIMA, José Dantas de.Gestão de resíduos sólidos urbanos no Brasil. [S. L.]: ABES, 2001. $267 \mathrm{p}$.

MARIGA, Jandira Turatto. Desenvolvimento, implementação e avaliação de um programa de aprendizagem ambiental para condomínios residenciais: enfoque em resíduos

sólidos. Cascavel: EDUNIOESTE, 2010. 110 p.

MARTINHO, M. da G. M; GONÇALVES, M. G. P. Gestão de resíduos. Lisboa: Universidade Aberta, 2000. 261 p.

MILANEZ, Bruno; MASSUKADO, Luciana Miyoko (Coord.). Diagnóstico dos Resíduos

Sólidos Urbanos: Relatório de Pesquisa. Brasília: Ipea - Instituto de Pesquisa Econômica

Aplicada, 2012. 78 p. Disponível em:

<http://ipea.gov.br/portal/images/stories/PDFs/relatoriopesquisa/121009_relatorio_residuos_s olidos_urbanos.pdf>. Acesso em: 10 jun. 2017.

MONTEIRO, José Henrique Penido et al. Manual de Gerenciamento Integrado de resíduos sólidos. Coordenação técnica Victor Zular Zveibil. Rio de Janeiro: IBAM, 2001. 200 p. (Patrocínio: Secretaria Especial de Desenvolvimento Urbano da Presidência da República - SEDU/PR). Disponível em <http://www.ibam.org.br/media/arquivos/estudos/manual_girs.pdf> Acesso em: 4 jun. 2017. MONTEIRO, Teófilo Carlos do Nascimento. (Coord.). Gestão integrada de resíduos sólidos municipais e impacto ambiental: Guia para Preparação, Avaliação e Gestão de Projetos de Resíduos Sólidos Residenciais. Rio de Janeiro: FIOCURZ, 2001. 417 p.

MORAES, Luiz Roberto Santos; BORJA, Patrícia Campos. Gestão integrada e sustentável e tecnologias apropriadas para manejo de resíduos sólidos urbanos - um outro paradigma. In: CONGRESSO INTERAMERICANO DE RESÍDUOS SÓLIDOS DE AIDIS, 3. 2009.

Anais... Buenos Aires: AIDIS, 2009. 1 CD ROM.

PARRA, Rogério et al. Acondicionamento e coleta de lixo. In. D'ALMEIDA, Maria Luiza Otero de; VILHENA, André. Lixo Municipal: manual de gerenciamento integrado. São Paulo: Instituto de Pesquisas Tecnológicas (IPT) e Compromisso Empresarial para Reciclagem (CEMPRE), 2000. p. 45-77.

PAVAN, Daniela Borges. Indicadores de sustentabilidade do programa coleta seletiva solidária em três bairros de Criciúma, SC. 2014. 88 f. Trabalho de conclusão de curso 
(Graduação em Engenharia Ambiental) - Universidade do Extremo Sul Catarinense, Criciúma, 2014.

PHILIPPI JR, A.; AGUIAR, A. O. Resíduos Sólidos: Características e Gerenciamento. In: PHILIPPI JR, A. (ed.). Saneamento, saúde e ambiente: fundamentos para um desenvolvimento sustentável. . São Paulo, 2005. p. 267-321.

RIBEIRO, José Claudio Junqueira; AMARAL, Carlos Henrique Carvalho. Gestão e Gerenciamento de Resíduos Sólidos. In.: COSTA, Beatriz Souza; RIBEIRO, José Claudio Junqueira. (Org.) Gestão e Gerenciamento de Resíduos Sólidos - Direitos e Deveres. 1. ed. Rio de Janeiro: Editora Lumen Juris, 2013. p. 39-56.

SC ENGENHARIA E GEOTECNOLOGIA LTDA. Plano Municipal de Gestão Integrada de Resíduos Sólidos de Criciúma: Meta 2 - Diagnóstico dos Resíduos Sólidos. Florianópolis: SC Engenharia e Geotecnologia, 2016. 381 p. Disponível em: $<$ http://www.camaracriciuma.sc.gov.br/upload/2016/10/18/PE048-16 PMGIRS META_2_Diagnostico_PMGIRS_Criciuma.pdf >. Acesso em: 07 jul. 2017. SC ENGENHARIA E GEOTECNOLOGIA LTDA. Plano Municipal de Gestão Integrada de Resíduos Sólidos de Criciúma: Meta 4 e 5 - Planejamento das ações e agendas de implementação do PMGIRS e monitoramento. Florianópolis: SC Engenharia e Geotecnologia, 2016. 411 p. Disponível em: <http://www.camaracriciuma.sc.gov.br/upload/2016/10/18/PE048-16 PMGIRS METAS_4_5Prognostico_PMGIRS_Criciuma.pdf>. Acesso em: 30 jun. 2017.

SCHNEIDER, Vania Elisabete. Manual de gerenciamento de resíduos sólidos de serviços de saúde. 2. ed. rev. e ampl Caxias do Sul, RS: EDUCS, 2004. 319 p.

UNIVERSIDADE DO EXTREMO SUL CATARINENSE. Instituto de Pesquisas Ambientais e Tecnológicas - IPAT. Estudo de concepção para implantação de sistema de gestão de resíduos sólidos urbanos (RSU) no município de Criciúma, SC: Diagnóstico da situação atual relativa ao sistema existente e aspetos socioeconômicos. Criciúma: UNESC/IPAT, 2013. $188 \mathrm{p}$.

ZANTA, V. M.; MARINHO, M. J. M. do R.; LANGE, L. C.; PESSIN, N. Resíduos Sólidos, Saúde e Meio Ambiente: Impactos associados aos lixiviados de aterro sanitário. In: CASTILHOS JUNIOR, Armando B. (Coord.). Gerenciamento de resíduos sólidos urbanos com ênfase na proteção de corpos d'água: prevenção, geração e tratamento de lixiviados de aterros sanitários. Rio de Janeiro: ABES, 2006. p. 1-15.

ZANTA, Viviana Maria; FERREIRA, Cynthia Fantoni Alves; Gerenciamento Integrado de Resíduos Sólidos Urbanos. In: CASTILHOS JÚNIOR, Armando Borges et al. (Org.).

Resíduos sólidos urbanos: aterro sustentável para municípios de pequeno porte. 1. ed. São Carlos SP: Rima Artes e Textos, 2003. p. 1-18. 